\title{
Antiretroviral and Antiparasitic Therapy Management in an Expatriate Patient with Loiasis and HIV: A Case Report
}

Riccardi $N^{1 *}$, Magnè $F^{1}$, Saffioti $C^{1}$, Dodi $F^{1}$, Ferrazin $A^{1}$, Ratto $S^{1}$, Di Biagio $A^{1}$, Viscoli $C^{1}$

Division of Infectious Disease, IRCCS AOUS San Martino-IST-University of Genoa-Italy

\begin{abstract}
Loa loa filariasis, endemic in Western and Central Africa, is rarely observed in Italy (about 100 cases reported between 1993 and 2013). Clinical manifestations of loiasis are different between expatriates and natives: asymptomatic infestation and eye involvement are more common in natives, while Calabar swelling, itching and urticaria are mainly seen in expatriates. Although a geographically restricted infection, it is not impossible to face loiasis among immigrants and travellers. Due to the HIV high prevalence in the same areas, also in apparent absence of risk factors or HIV related symptoms, an HIV test should be offered to people coming from these countries to detect unknown infections. We describe a case of symptomatic loiasis in an expatriate man, who was hospitalized for loiasis and discovered to be also HIV-1-positive; in our patient, the diagnosis of HIV infection forced us to start highly-active-antiretroviral therapy (HAART) and antiparasitic treatment simultaneously.
\end{abstract}

\section{Keywords: Loiasis; HIV; Treatment; HAART}

\section{Introduction}

Loiasis, caused by the filarial nematode Loa loa, is also known as African eye-worm, because the adult worm occasionally move across the eye of infected people. Loa loa is a little diurnal nematode (male 30 $\times 0.4 \mathrm{~mm}$, female up to $60 \times 0.5 \mathrm{~mm}$ ) that can inhabit the lymphatics and subcutaneous tissues of humans. Loiasis is a vector-borne infection and the main vectors (deerflies) are day-biting flies from two species of the genus Chrysops, C. silacea and C. dimidiata which harbor the infective larvae $(2 \mathrm{~mm} \times 25 \mu \mathrm{m})$ that penetrate the skin of the human host when the vector takes a blood meal. Other Chrysops species are of local importance, especially in the periphery of the transmission zone which is only located in Africa mainly confined, according to Rapid Assessment Procedure for Loiasis (RAPLOA) study [1], to the equatorial rain forest regions of Central and West Africa. About 90 million people live in endemic areas for loiasis and Equatorial Guinea, both in rural and in the city centers, is one of the most affected country (Figure 1). Although a geographically restricted infection, globalization, human migration and international travels to and from endemic regions are effecting the burden of loiasis around the world; about 100 cases were

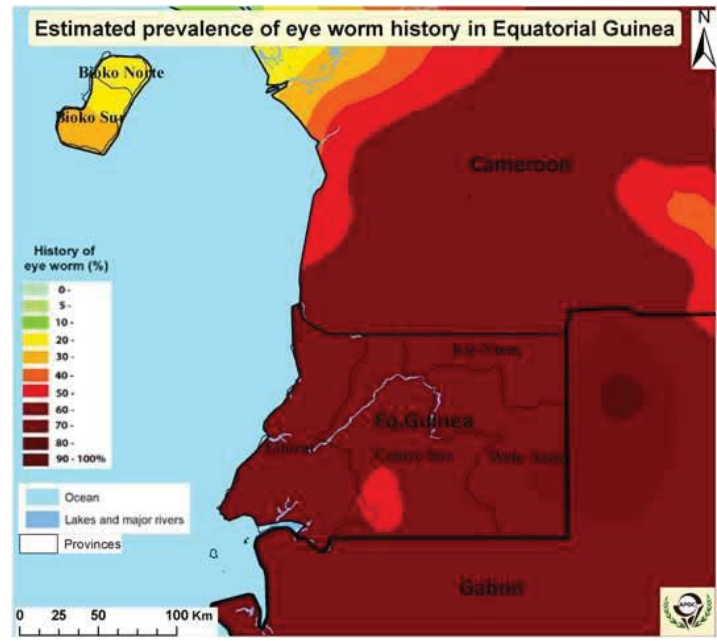

Figure 1: Pruriginous skin lesions due to Loa-loa filariasis. detected in Italy between 1993 and 2013 [2]. Most people infected with Loa loa are asymptomatic and the pathogenesis of loiasis is poorly understood. Clinical signs of loiasis may appear after five months from the infection: eye worm sign and asymptomatic infestation are more common in natives of endemic regions, while Calabar swellings, which is defined by episodic angioedema due to hypersensitive reactions to migrating adult parasites and/or microfilaria [3], pruritus and urticaria are more common in expatriates who were exposed to loiasis during adulthood. Hypereosinophilia, high antibody titres to filarial antigens and microfilaremia are common laboratory findings [4]. According to the Center for Disease Control (CDC) diethylcarbamazine (DEC) (5-10 $\mathrm{mg} / \mathrm{Kg}$ daily in divided doses for 2-4 weeks) is the treatment of choice, unfortunately it is not available in many countries and it can cause serious adverse reactions related to Loa loa high microfilarial density, including encephalopathy and death [5]. Alternative therapeutic regimen may include albendazole ( $400 \mathrm{mg}$ bis in die), used to decrease microfilaremia, followed by a single administration of ivermectin (200 $\mu \mathrm{g} / \mathrm{Kg}$ orally) to kill adult worms. In Sub-Saharian Africa 24.7 million people live with HIV infection and there were 1.5 million new infection in 2013 [6]. According to UNAids, in 2014, in Equtorial Guinea there were an estimated 32,000 people living with $\mathrm{HIV}, 6.2 \%$ of the adults aged 15 to 49 . Due to HIV high prevalence in endemic countries for loiasis, also in apparent absence of risk factors or HIV related symptoms, an HIV test should be offered to people coming from these countries to detect unknown infections. It is important to evaluate possible drugdrug interactions between HAART and antiparasitic treatment to avoid side effects and therapeutic failure. We describe a case of symptomatic loiasis in an expatriate man, who was hospitalized for loiasis and

*Corresponding author: Niccolò Riccardi, Infectious Disease Clinic, IRCCS AOU San Martino Hospital IST, University of Milan, IRRCS AOU San Martino University Hospital-IST, L.go R. Benzi, 10, 16132 Genoa, Italy, Tel: +39 010 5554652; E-mail: niccolo.riccardi@yahoo.it

Received August 31, 2015; Accepted September 01, 2015; Published September 17, 2015

Citation: Riccardi N, Magnè F, Saffioti C, Dodi F, Ferrazin A, et al., (2015) Antiretroviral and Antiparasitic Therapy Management in an Expatriate Patient with Loiasis and HIV: A Case Report. J Trop Dis 4: 178. doi:10.4172/2329891X.1000178

Copyright: (๑) 2015 Riccardi N, et al. This is an open-access article distributed under the terms of the Creative Commons Attribution License, which permits unrestricted use, distribution, and reproduction in any medium, provided the original author and source are credited. 
Citation: Riccardi N, Magnè F, Saffioti C, Dodi F, Ferrazin A, et al., (2015) Antiretroviral and Antiparasitic Therapy Management in an Expatriate Patient with Loiasis and HIV: A Case Report. J Trop Dis 4: 178. doi:10.4172/2329-891X.1000178

discovered to be also HIV-1-positive; in our patient, the diagnosis of HIV infection forced us to start highly-active-antiretroviral therapy (HAART) and antiparasitic treatment simultaneously.

\section{Case Report}

A 74 years old Italian man, who had been living since 2006 in Equatorial Guinea, was admitted to our Infectious Disease Clinic on December $15^{\text {th }} 2014$ due to itchy skin lesions at lower limbs (Figure 2 ), eye discomfort with detection of a worm in his conjunctiva and mild fever $\left(37.2^{\circ} \mathrm{C}\right.$ ). His white blood cell count was $5730 / \mathrm{mm}^{3}$ (normal values $4500-9800 \mathrm{~mm}^{3}$ ) with $15 \%$ eosinophils (normal values $0-0.20$ $\mathrm{mm}^{3}$ ), IgE $483 \mathrm{kU} / \mathrm{L}$ (normal values $0-240 \mathrm{kU} / \mathrm{L}$ ) and $3.4 \mathrm{mg} / \mathrm{L}$ of C-reactive protein (normal values $0-5.0 \mathrm{mg} / \mathrm{L}$ ). His medical history revealed complicated malaria in 2005 and pulmonary embolism in 2011 in treatment with warfarin (2,5 mg orally once daily). On physical examination, apart from the skin lesions, nothing remarkable was noticed. Malaria rapid diagnostic test resulted negative. Serologic ELISA IgG test for filariasis, performed at the Istituto Superiore di Sanità in Rome, resulted positive. Microscopic examination of blood films performed daily at noon for 4 days revealed 22 microfilariae per $9 \mathrm{~mL}$ of blood; the microfilaremia was then confirmed by the Center for Tropical Disease in Negrar, Verona, Italy. Despite the absence of any clinical sign, the patient was offered an HIV screening test according to our opt-out policy. HIV ELISA-test and HIV IMMUNOBLOTtest resulted positive; his CD4+ T cell count was $600 / \mathrm{mmc}$ and the HIV-1-viral load was 262.500 copies/mL. The patient did not report any risk factor for HIV infection such as unprotected sex, previous blood transfusion or use of intravenous drugs. Diethylcarbamazine citrate (DEC), the drug of choice for the treatment of loiasis according to the CDC, is not available in Italy. Therefore, a 21 days course of albendazole ( $400 \mathrm{mg}$ orally bis in die) was chosen followed by a single administration of ivermectin $(200 \mu \mathrm{g} / \mathrm{Kg}$ orally). Ivermectin clears Loa Loa microfilaraemia while albendazole has been tested as adult worm antiparasitic. Raltegravir (400 mg orally bis in die) and emtricitabine/ tenofovir disoproxil (200/245 mg orally once daily) were selected for HAART to avoid possible drug-drug interaction with albendazole [7];

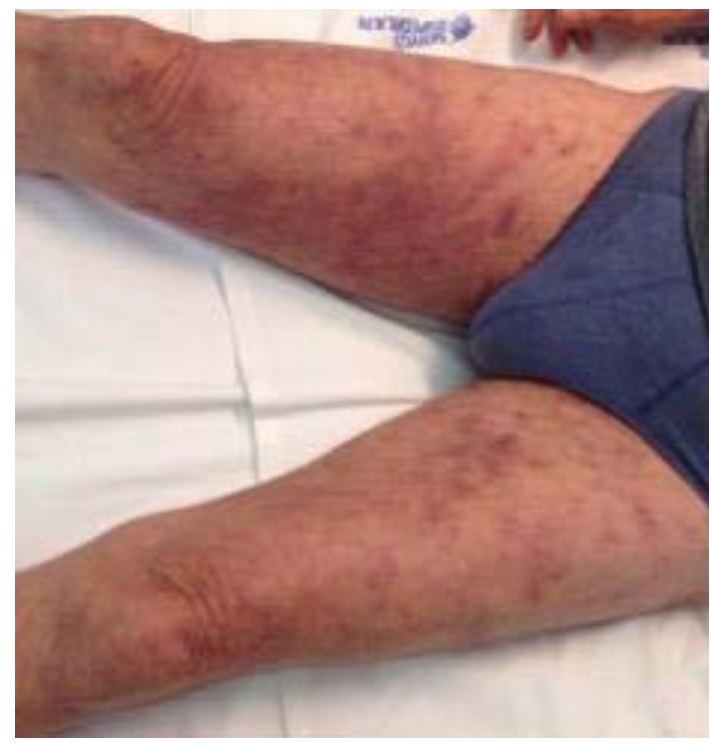

Figure 2: Itchy skin lesions at lower limbs. similarly, the modification of anticoagulant treatment with dabigatran etexilate (150 mg orally bis in die) was necessary to avoid possible drugdrug interaction with albendazole [8]. After 4 weeks, the eosinophils dropped to $8.8 \%$, with a concomitant decrease of HIV-RNA to 89 copies/mL. After 12 weeks HIV-1-RNA was undetectable ( $<50$ copies/ $\mathrm{ml}), \mathrm{CD} 4+$ count was $670 / \mathrm{mmc}$ and eosinophils count was in range (5.7\%). No side effect was reported during treatment and the patient is currently in follow-up and asymptomatic [9].

\section{Conclusion}

Starting antiretroviral therapy early is becoming a milestone of HIV treatment [10], nevertheless it is mandatory to minimize side effects and avoid drug-drug interactions. Albendazole rapidly undergoes extensive first-pass metabolism in the liver generating albendazole sulfoxide, albendazole active metabolite, through CYP3A4. Ritonavir boostered protease inhibitors and non-nucleoside reverse transcriptase inhibitors (NNRTIs) may increase/decrease albendazole sulfoxide plasmatic levels due to CYP3A4 inhibition/induction. For instance, long term administration of ritonavir has the potential to reduce plasma concentrations of active albendazole [11], while protease inhibitors may increase albendazole sulfoxide plasmatic level. According to in vitro data [12], ivermectin seems to be primarily metabolized by CYP3A4 as well, suggesting that, theoretically, could be an interaction between ivermectin and NNRTIs, which may potentially decrease ivermectin levels and an interaction with protease inhibitors, which may increase ivermectin levels. There is no clinically significant interaction expected between albendazole and nucleoside reverse transcriptase inhibitors as well as between albendazole and integrase inhibitors [13]. During loiasis treatment we minimized the risk of side effects and therapeutic failure selecting emtricitabine/tenofovir disoproxil + raltegravir. Due to one of warfarin hepatic metabolism path, from 6- and 8-hydroxywarfarin to 10-hydroxywarfarin by CYP3A4, anticoagulant treatment was switched during antiparasitic somministration and restored at the end of the treatment. No side effects were reported during the 21 days course of antiparasitic treatment. Although a geographically restricted infection, it is not impossible to face loiasis among immigrants and travellers, therefore western physicians should be familiar with both typical and atypical presentation and choose carefully the appropriate treatment avoiding deleterious drug-drug interactions.

\section{References}

1. Zouré HG, Wanji S, Noma M, Amazigo UV, Diggle PJ, et al. (2011) The geographic distribution of Loa loa in Africa: results of large-scale implementation of the Rapid Assessment Procedure for Loiasis (RAPLOA). PLoS Negl Trop Dis 5: e1210.

2. Gobbi F, Postiglione C, Angheben A, Marocco S, Monteiro G, et al. (2014) Imported loiasis in Italy: an analysis of 100 cases. Travel Med Infect Dis 12 713-717.

3. Richard LG, David HW, Peter FW (2011) Tropical Infectious Diseases: Principles, Pathogens and Practice. (3rdedn), Philadelphia: Churchill Livingstone.

4. Antinori S, Schifanella L, Million M, Galimberti L, Ferraris L, et al. (2012) Imported Loa loa filariasis: three cases and a review of cases reported in nonendemic countries in the past 25 years. Int J Infect Dis 16: e649-e662.

5. Klion AD, Ottesen EA, Nutman TB (1994) Effectiveness of diethylcarbamazine in treating loiasis acquired by expatriate visitors to endemic regions: long-term follow-up. J Infect Dis169: 604-610.

6. Global report (2013) UNAIDS report on the global AIDS epidemic.

7. Asteinza J, Camacho-Carranza R, Reyes-Reyes RE, Dorado-González VV, Espinosa-Aguirre JJ (2000) Induction of cytochrome P450 enzymes by albendazole treatment in the rat. Environ Toxicol Pharmacol 9: 31-37.

8. Stangier J (2008) Clinical pharmacokinetics and pharmacodynamics of the oral 
Citation: Riccardi N, Magnè F, Saffioti C, Dodi F, Ferrazin A, et al., (2015) Antiretroviral and Antiparasitic Therapy Management in an Expatriate Patient with Loiasis and HIV: A Case Report. J Trop Dis 4: 178. doi:10.4172/2329-891X.1000178

Page 3 of 3

direct thrombin inhibitor dabigatran etexilate. Clin Pharmacokinet 47: 285-295

9. National Institute of Health (2015) Starting antiretroviral therapy early improves outcomes for HIV-infected individuals.

10. Nix DE, Adam RD, Auclair B, Krueger TS, Godo PG, et al. (2004) Pharmacokinetics and relative bioavailability of clofazimine in relation to food orange juice and antacid. Tuberculosis (Edinb) 84: 365-373.
11. Rodrigues AM, Hueb M, Nery AF, Fontes CJ (2007) Possible cardioprotective effect of angiotensin-converting enzyme inhibitors during treatment of American tegumentary leishmaniasis with meglumine antimoniate. Acta Trop 102: 113118

12. Kay S, Saye K, David B, Natalie P, Mohammed L, et al. (2013) Drug-Drug Interactions Between Antiretrovirals and Drugs Used in the Management of Neglected Tropical Diseases. AIDS 27: 675-686.

13. Laurence SK, Zhi-Yi Z (1997) Human P450 metabolism of warfarin Pharmacology \& Therapeutics 73: 67-74. 